\title{
Selection of optimal portfolios of interdependent real options
}

\author{
Bogdan Rebiasz ${ }^{\mathrm{a}^{*}}$
}

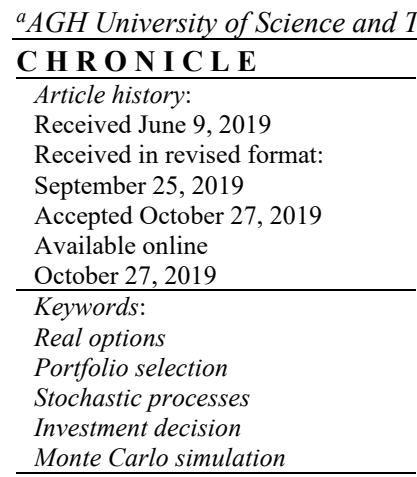

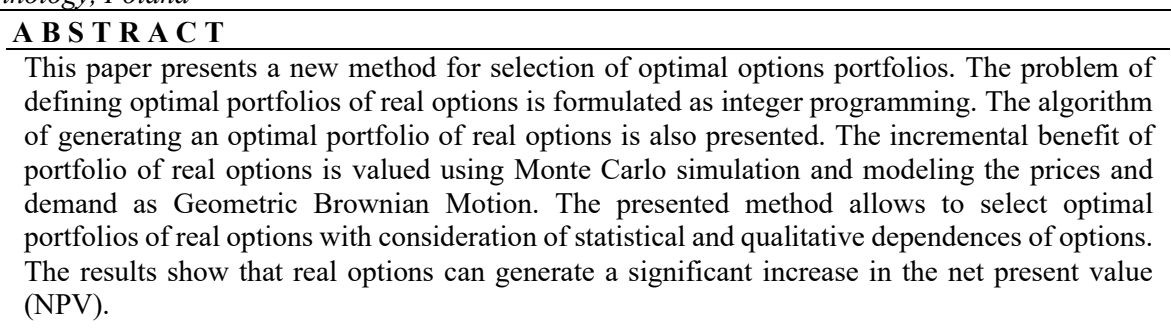

This paper presents a new method for selection of optimal options portfolios. The problem of defining optimal portfolios of real options is formulated as integer programming. The algorithm of generating an optimal portfolio of real options is also presented. The incremental benefit of portfolio of real options is valued using Monte Carlo simulation and modeling the prices and demand as Geometric Brownian Motion. The presented method allows to select optimal portfolios of real options with consideration of statistical and qualitative dependences of options. The results show that real options can generate a significant increase in the net present value (NPV).

\section{Introduction}

In the 1950s portfolio theory was discovered and developed by Markowitz (1952). The financial portfolio analysis is based on the concept of diversification. Diversification is decisive for the creation of an efficient portfolio. Thanks to it, we get the opportunity to reduce the variability of returns around the expected return (Markowitz, 1952). Markowitz diversification is understood as a combination of assets that are less than perfectly correlated. Thanks to diversification, we get a risk reduction while maintaining the level of portfolio returns (Francis, 1991). Markowiz (1952) definied the efficient portfolio as any asset or combination of assets that has the maximum expected return in its risk class or the minimum risk at its level of expected return. Capital budgeting is the process of building an enterprise investment program based on the analysis of investment opportunities. Such a program can be defined as a portfolio. Usually an efficient investment projects portfolio is sought. An efficient portfolio of investment projects is one which provides (e.g. Zuluaga et al., 2007; Dickinson, 2001; Rebiasz et al., 2017):

- the highest $N P V$ at a given accepted level of risk,

- the lowest risk at a given accepted $N P V$ for the portfolio.

There are currently many works that deal with the construction of such portfolios. In the process of creating portfolios, investment projects are treated statically, and potential options generated by these projects are not analyzed (Rebiasz et al., 2013). Myers (1977) introduced real options as a new area of

* Corresponding author

E-mail address: brebiasz@zarz.agh.edu.pl (B. Rebiasz)

(C) 2020 by the authors; licensee Growing Science, Canada. doi: $10.5267 /$ j.dsl.2019.10.003 
financial research. The concept of real options was based on the idea that real assets (investment projects) could be evaluated based on the methods defined for financial options. Real options theory modifies $N P V$, by allowing that subsequent decisions can modify the project once it is undertaken. $N P V$ makes no provision for this flexibility of the project and consequently undervalues its benefits. Contemporary literature focuses mainly on the valuation of individual options (i.e. one type of operating option at a time). However, managerial flexibility embedded in investment projects should be analyzed in the form of a collection of real options. The concept of portfolios of real options has been discussed by several authors (e.g. Betge, 1995; Trigeorgis, 1993; Brosch, 2001; Brosch, 2008; Hirsa \& Neftci, 2014). Hirsa and Neftci, (2014) define the portfolio as a particular combination of assets in question. According to Brosch (2008) portfolios of real options are combinations of multiple risky assets and multiple real options written on these assets subject to constrains. Most common portfolios of real options consist of switching options (Kodukula \& Papudesu, 2006). A switching option gives the flexibility of being able to switch resources, assets or technology in the future. Portfolios of real options unlike portfolios of financial options have non-additive character (Trigeorgis, 1993). Two separate financial options, e.g. to buy stock of company $A$ and company $B$ are independent from one another. Therefore, they can be treated separately while defining the portfolio of options. This portfolio will have an additive character. Whilst, real options interact in various ways. This is the reason why they cannot be valued independently from one another. Therefore, the value of portfolio of real options does not equal the sum of the options it is composed of. This is an important difficulty that arises when trying to develop formal methods of defining such portfolios. When multiple real options on multiple underlying assets are considered, the interactions in the company's portfolio increase. In order to seize all possible portfolio effects, it is important to analyze multiple underlying assets with multiple real options simultaneously. This problem has not been adequately discussed in the real options literature, meanwhile, is crucial for researchers and pracitioners (Smith \& Thompson, 2008). By defining the optimal portfolio of real options, the decision maker in practice determinies the company's strategy. Namely, he defines the way the company is planning to create value in the future.

This paper presents a new method of defining optimal portfolio of real options. To define the optimal design of the real options portfolio, we need to choose the assets and options embedded in these assets, which ensures the highest value for the portfolio taking into account different constraints. Proposed method takes into account multiple correlated and interdependent options defined on multiple assets. The procedure for defining such portfolio combines stochastic simulation with mixed-integer programming. Such a model has not yet been presented in the literature. However, you can find authors who are trying to solve this problem using the Cox-Ross-Rubinstein (CRR) model (e.g. Trigeorgis and Kasanen, 1991; Trigeorgis, 1993; Childs et al., 1998; Brosch, 2008). This problem is discussed in more detail in Section 3.

\section{Classification of the interdependencies of real options}

Real options may be interdependent for a range of reasons (Trigeorgis, 1993; Brosch, 2001). The assessment of a particular investment opportunity in a risky world has to take into account the stochastic correlation of this opportunity with all other opportunities. We speak of a statistical relationships of real options when a correlation exists between the benefits generated by these options (Dickinson et al., 2001; Santhanam \& Kyparisis, 1996; Zuluaga et al., 2007). This correlation is due to the correlation of the parameters used to calculate efficiency. For example, there is a correlation of the prices of an enterprise's products and raw material prices. In addition the volume of the markets for different product ranges are correlated (Rebiasz, 2013). As a result, cash flows generated by these real options are correlated. This type of interdependence can be partially eliminated through diversification. Beside these stochastic interdependencies, real options can influence each other on a technical or physical level. In order to clearly distinguish them from the stochastic relationships, they are defined as qualitative interactions (Hax, 1985; Betge, 1995; Trigeorgis \& Kasanen, 1991; Trigeorgis, 1993; 
Brosch, 2001). According to Brosch (2008) and Trigeorgis (1993) portfolio interactions on the real options level and on the real asset level can be distinguished (see Fig. 1).

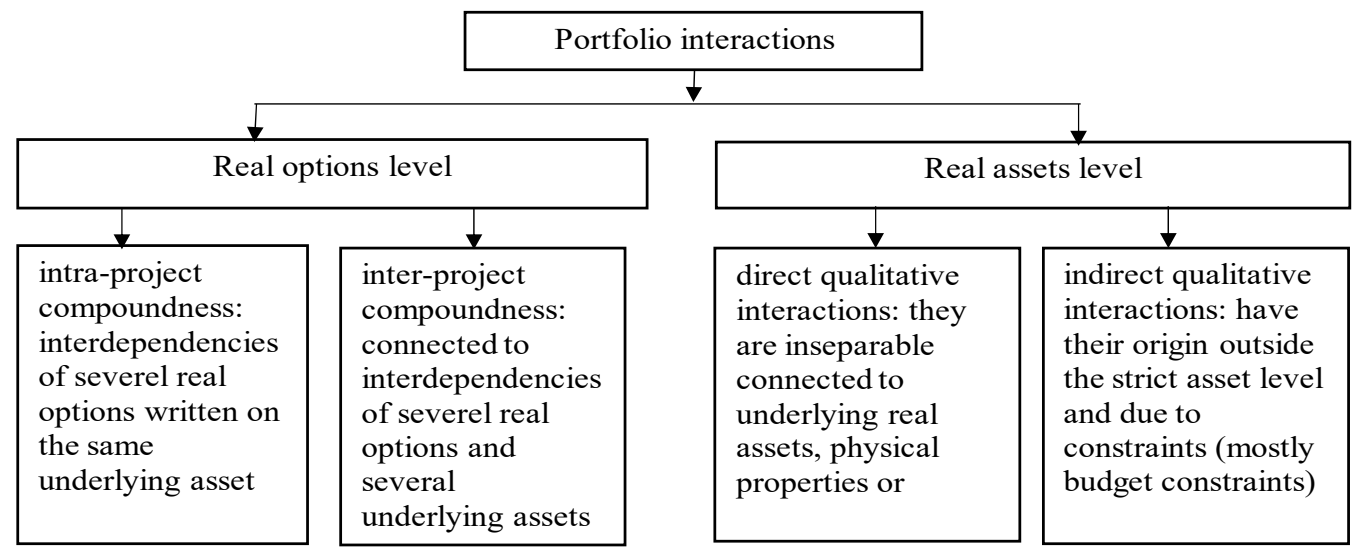

Fig. 1. Portfolio interactions (Trigeorgis,1993; Brosch, 2008)

Interactions of real options written on the same underlying asset are defined as intra-project compoundness (Trigeorgis, 1996). Real options on the same underlying asset interact in an intrinsic way, therefore they cannot be valued independently from one another, but must necessarily be modeled as a compound option (Betge, 1995; Brosch, 2001; Trigeorgis \& Kasanen, 1991). These interactions can occur in various forms. They can be partial if there are positive or negative synergies in options. Interactions can also take the form of binary dependencies if the options are mutual exclusive or depend on one another (Brosch, 2008). On the one hand options can be strictly substitutive. This is the case when options exclude each other, e.g. when they are designed for servicing the same markets. On the other hand options can be strictly complementary. This is the case when options may require that other options exist at the same time, e.g. the construction of a department producing a specific product requires the construction of departments preparing semi-finished products. These two relationships can also be gradual in the sense that the cash-flow of one option can be positively or negatively affected by the existence of other options to a different extent. Furthermore, the interactions can always be mutual or one-way. Valuation of these interacting real options schould be realized by the valuation of all the real options and underlying asset as a whole (Brosch, 2008; Trigeorgis, 1993). The reason for that is the fact that options on the same real assets are linked through this asset. By exercising any option the underlying asset is affected and with it, all other options tied to it (Trigeorgis, 1993). As an example, one can indicate here the option to abandon. After exercising it, all other options become outdated. What's more, the order in which the options are exercised influences the value of the portfolio. Therefore, when the number of options within a portfolio exceeds two an order of option execution is important and should be optimized (Smith \& Thompson, 2008).

Following the same logic, an analogous effect is identified for several, interdependent underlying assets which are denoted as inter-project compoundness (Trigeorgis, 1996). Both inter-project and intraproject compoundness must be considered in the context of portfolios of real options. Brosch (2001) divides interactions on the real asset level into direct and indirect ones. Direct qualitative interactions result from the investment plan. They can also result from interactions with completed investments that continue to generate cash flows. These interactions arise from the physical properties of investment projects. The nature of these interactions is similar to the nature of interaction on the option level. Indirect qualitative interactions are associated with constraints that go beyond the investment plan. In addition, they are not directly related to the considered investment opportunities. This kind of interaction results from general conditions and restrictions that do not necessarily are connected with the investment projects. These constraints result from the specificity of the company. They are qualitative because they do not result from stochastic relationships and cannot be avoided by diversification (Betge, 1995; Brosch, 2008). Indirect qualitative interactions usually result from capital 
rationing. Therefore, they could be avoided, e.g. by finding new financing resources (Brosch, 2008; Wasilewska, 2013; Trigeorgis, 1993).

\section{Real Options Analysis in a Portfolio Context}

Meier et al. (2001) discuss a portfolio of real options subject to a capital expenditure constraint. They propose two approaches for defining portfolios of real options. The first approach is based on the assumption that the value of the portfolio is calculated as the sum of the values of the options in the portfolio. The authors define the problem of finding the portfolio of options that has maximal value and fulfils the capital expenditure constraint. This problem is formulataed as traditional knospak problem. The model is static and the interactions of real options are not considered. This approach is similar to traditional capital budgeting presented in many works (e.g. Dickinson et al., 2001; Chien, 2004, Rebiasz, 2013). However, in this model, the $N P V$ was replaced by the option value. In the second approach, the authors define an alternative optimisation model. This model uses scenarios to depict a set of possible future states. The optimal soltion define a number of state-dependent optimal portfolios that determines a dynamic investment strategy. The authors use here integer programming. In addition, Meier et al. (2001) discus an efficient algorithms specific to the defined problems. Also in this model, interactions of real option are not considered. The problem of the optimal portfolio of real options is also discussed in the works (Brosch, 2001; Brosch, 2008). They show how far a stand-alone analysis differs from a portfolio-analysis in the context of real options. Brosh places special emphasis to modeling interactions of options. Furthemore he analyse path-dependencies and define dynamic budget constraints. In his concepts, he uses $C R R$ models and binary programming. When constructing a portfolio of real options, problems involving inter-project interactions are particularly relevant. In this context, Childs et al. (1998) discuss the effect of project interactions on investment decisions and project values in a real options framework. They consider a two mutually exclusive projects. The firm may invest in the development stage of this projects and then may select only a single project to implement. The authors argue that sequential development is better than parallel development when projects are statisticly dependent, and when they are highly capital-intensive, are short term in nature, and have relatively low volatility. They also investigate the optimal ordering for sequential projects. Finally, the authors show that the optimal ordering of such projects does not always begin with the most profitable project. Similarly, Childs and Triantis (1999) consider the parallel development of two R\&D projects taking into consideration interaction between project cash flows. They analyse the projects in the presence of a budget constraint that prevents the firm from developing projects in parallel. The authors point out, inter alia, that if one project significantly dominates another early in the development stage, the option to accelerate the lead project is likely to be more valuable than the option to exchange projects. Gustafsson and Salo (2005) define methods for selecting R\&D projects portfolio. They developed contingent portfolio programming, which extends earlier approaches becouse provides guidance for the selection of an optimal projects portfolio that is compatible with the decision maker's risk attitude. This model was used to solve the R\&D projects portfolio problem. However, it could be used to a variety of investment problems where the dynamics and interdependencies of investment projects must be taken into consideration. Denardo and Rothblum (2004) define the problem of finding an investment strategy (in the R\&D area) that maximizes expected utility, either with a linear or an exponential utility function. The authors emphasis on finding an effective algorithm to solve the problem. They propose a stochastic search algorithm with a sequential compound decision process. A review of R\&D specific investment problems is found in Chien (2004), Kavadias and Loch (2004) and Gustafsson and Salo (2005).

Vassolo et al. (2004) identify two sources of potential interactions among real options. First, they investigate the effects of correlations between the outcomes in different options. Second, they analyze the effects of investments that are fungible across project options. The authors show that under different conditions multiple options can be sub-additive (due to redundancies in outcomes) or super-additive 
(due to fungible inputs). Rose (1998) and Bowe and Lee (2004) consider the intra-project interactions of options on infrastructure projects, following the framework presented in Trigeorgis (1993). Kester (1993) analyzed inter-project dependence in the context of growth options. Kogut and Kulatilaka (1994), Kulatilaka (1995) and Huchzermeier and Cohen (1996) develop a stochastic dynamic programming formulation for the valuation of global manufacturing strategy options for multinational corporation. They consider a global manufacturing network under exchange rate risk, with switching options between different manufacturing strategies contingent on exchange rate realizations. Triantis and Hodder (1990) develop a method for valuing flexible production system using contingent claims pricing. They ilustrate their approach by analysing a flexible production system that can switch the production mix among two products with profit margin defined by function with stochastic parameters. Trigeorgis and Kasanen (1991) consider a portfolio perspective by considering compound synergistic effects between parallel projects. They discuss base of the decisions of managers and strategists. They emphasize that managers often take projects that have negative $N P V$ (e.g., R\&D projects) due to their flexibility, synergy strategic positioning etc. Wang and de Neufville (2004) explore real options in physical systems, such as hydropower stations. They modeled this options as path-dependent options. The authors uses stochastic mixed-integer programming to anage the path-dependency and interdependency features of this options. The presented approach can be used to a variety large-scale physical systems. Kasanen (1993) and Kasanen and Trigeorgis (1993) discuss staregic projects such as brand name, company image or new technology which may generate future investment opportunities. They present a new tools for analysing such investments and for managing investment opportunities over time. In the discuss the real options portfolio problem with budget constraints and different interdependencies of options which is usually formulated as a stochastic mixed-integer programming problem, based on the Cox-Ross-Rubinstein $(C R R)$ version of the binomial model. In the quoted literature, a typical way of taking synergies of the options into account is to model bundles of synergistic projects as new projects. Synergies just imply additional projects. In the case of complex interdependencies of options, such an approach can be cumbersome. In the case of an increase the number of options with complex interdependencies, the number of new projects may increase exponentially. Such a case occurs in many large corporations. This may make it difficult (or practically impossible) to build and solve mixed-integer programming task.

\section{Model and Methodology}

This section introduces the model and methodology for defining and valuating the optimal portfolios of real options. Firstly, the modelling of uncertainty using correlated Geometric Brownian Motion $(G B M)$ is described. Next, model for defining and valuating the optimal portfolios of real options is presented. In this paper product switch options and options to delay will be discussed. Product switch option refer to changes in the products manufactured. Such changes aim to adapt to changes in the market situation. An option to delay enables a decision maker to wait and take the investment project later.

\subsection{Modeling Uncertainty by correlated Geometric Brownian Motion (GBM)}

$G B M$ is a special case of Brownian motion or Wiener process. The variable $q$ follows $G B M$, if it satisfies the diffusion equation (Bastian-Pinto et al., 2009; Copeland et al., 2015; Marathe \& Ryan, 2005; Ozorio et al., 2013; Wattanarat et al., 2010).

$$
d q_{t}=\mu q_{t} d t+\sigma q_{t} d w
$$

where $d w_{t}=\varepsilon_{t} \sqrt{d t}$ is the standard increment of Wiener process, and $\mu$ and $\sigma$ are drift parameter and standard deviation parameter, respectively. The parameter $\varepsilon_{t}$ has identical independent standard normal distribution. The drift $(\mu)$ and standard deviation parameters $(\sigma)$ of $G B M$ can be estimated using the sample mean and the standard deviation of the log return of the time series of the analyzed variable. A detailed description one can find in the literature (see Marathe \& Ryan, 2005; Hirsa \& Neftci, 2014). 
Let $\Delta$ be the given time interval between two observations. For example, equals to one between $q_{t}$ and $q_{t-1}$. Based on Eq. (1), we can write the formulas for the prediction $q_{t}$ (Bastian-Pinto et al., 2009; Copeland et al., 2015; Marathe \& Ryan, 2005; Ozorio et al., 2013; Wattanarat et al., 2010).

$$
q_{t}=q_{t-1} \exp \left[\left(\mu-\frac{\sigma^{2}}{2}\right) \Delta+\varepsilon_{t} \sigma \sqrt{\Delta}\right] \text {. }
$$

When estimating economic efficiency we usually encounter many correlated uncertain variables. Suppose we have $I$ such variables. To take into consideration the correlation of the uncertain variables, the set of independent variables $\mathcal{E}_{i t} ; i=1,2, \ldots, I$ should be replaced with the set of correlated variables $\eta_{i t} ; i=1,2 \ldots, I$. Correlated values $\eta_{i t}$ can be derived based on values $\varepsilon_{i t}$. Here you can use the method of Cholesky decomposition of the correlation matrix described in the paper (Yang, 2005). The equations for generating correlated uncertain values can thus be written as follows.

$$
q_{i t}=q_{i t-1} \exp \left[\left(\mu_{i}-\frac{\sigma_{i}^{2}}{2}\right) \Delta+\eta_{i t} \sigma_{i} \sqrt{\Delta}\right]
$$

Eq. (3) can be used in Monte Carlo simulation to estimate $N P V$ of the static optimal investment portfolio. When estimating of the optimal real options portfolio value, a Monte Carlo simulation must be carried out under the assumption that the uncertain variables involved follow a risk-neutral GBM. In this case, Eq. (4) should be used instead of Eq. (3) (Brosch, 2001; Muharam, 2011).

$$
q_{i t}=q_{i t-1} \exp \left[\left(\mu_{i}-\pi-\frac{\sigma_{i}^{2}}{2}\right) \Delta+\eta_{i} \sigma_{i} \sqrt{\Delta}\right]
$$

Risk-premium $(\pi)$ estimation can be done as described in Hull (2006) and used in several works such as Blank et al. (2009).

\subsection{Method of selecting of optimal real options portfolio}

The developed method of selecting optimal portfolios of real options is adapted to conditions that exist in enterprises realizing multi-stage production processes. One such industry is the metallurgical industry. Portfolios of real options is understand as combinations of multiple risky assets and multiple real options written on these assets. The proposed method interprets the portfolio problem as an optimization problem with the objective of maximizing portfolio value subject to constraints. This method allows to maximize the value of the portfolio, i.e., the combined value of the bundle of all underlying assets and all real options embedded in these underlying assets. Taking the above into consideration, we analyze investment projects. An investment project is understood to be a variant of the modernization of existing production department or a variant of the construction of new production department along with the possible construction or modernization of facilities in auxiliary departments. For simplifying the notation of the model, it is assumed that leaving the current state of the existing production department is one of its investment projects (project number 0 ). In the algorithm for the selection of optimal option's portfolios presented below, it is assumed that a project, defined as not changing the current state of department, is included in the implementation if no alternative project is classified to the realization. Each project can be implemented at a certain time interval (options to delay). In each period, it is possible to choose the company's sales structure that maximizes cash flows (product switch option). The optimization horizon is understood to be a number of years for which the net cash flows of the company are being forecasted. It is equal to the sum of the maximum delay in the implementation of investment projects and the longest life-cycle of the investment projects analyzed. The following notation is formally used for the model:

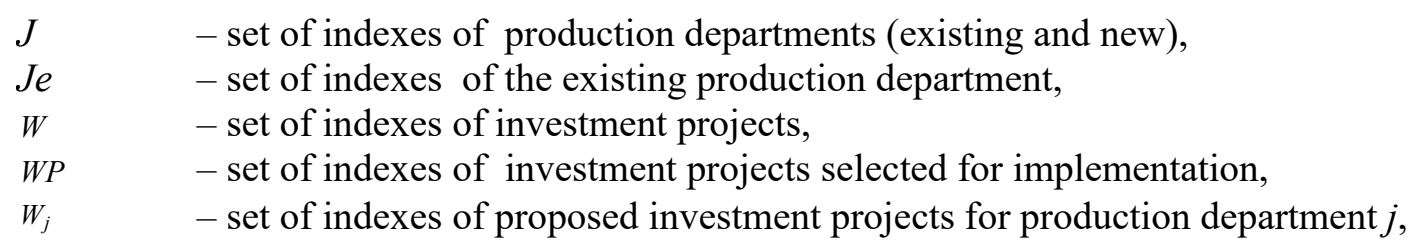


$N \quad-$ set of indexes of the mutually exclusive investment projects,

$W M_{n} \quad-$ set of indexes of the $n$-th set of mutually exclusive investment projects,

$I$, $\quad-$ set of indexes of products,

$I_{j} \quad-$ set of indexes of products produced in department $j$,

$D \quad-$ set of indexes of raw materials,

- forecasted outlays for investment project $w$ in department $j$ in year $\varsigma$ of its life

$\eta_{j w \varsigma} \quad$ cycle, $\varsigma=t-\tau$,

$\bar{\eta}_{t} \quad-$ limit of investment outlays in the year $t$,

$\bar{t}_{j w} \quad-$ economic life-cycle of project $w$ defined for department $j$,

th - optimization horizon

$\bar{\tau} \quad-$ maximum delay in the implementation of investment projects,

$\delta_{j w \tau} \quad-$ binary variable denoting acceptance for implementation or rejection of project $w$

in year $\tau$,

$\operatorname{Pr}_{i j w \tau} \quad$ - variable determining production of product $i$ in department $j$ after realization

$I C F_{t} \quad-$ variable determining cash flow of the company in year $t$,

$Z N_{t} \quad-$ variable determining net profit of the company in year $t$,

$S P_{t} \quad-$ variable determining revenue of the company in year $t$,

$K_{t} \quad-$ variable determining total cost of the company in year $t$,

$S R_{i t} \quad-$ variable determining sale of product $i$ in year $t$,

$Z K O_{t}-$ variable determining change in net working capital of the company in year $t$,

$\mathrm{KO}_{t} \quad-$ variable determining net working capital of the company in year $t$,

$R V_{t} \quad-$ variable determining residual value in year $t$,

$D A_{t} \quad-$ variable determining company's annual amortization in year $t$,

$G A_{t} \quad$ - variable determining company's fixed costs without amortization in year $t$,

- manufacturing capacity of department $j$ after realization of project $w$, in year $\varsigma$

capjw $_{j w} \quad$ of its life cycle, $\varsigma=t-\tau$

$s f_{i t} \quad-$ sales forecast for product $i$ in year $t$,

$m s_{i t} \quad-$ market share for product $i$ in year $t$,

$a c_{i t} \quad-$ forecasted apparent consumption of product $i$ in year $t$,

$s_{i t} \quad-$ price of product $i$ in year $t$,

- per unit consumption indicator of product $i$ used for producing product $z$

$m_{i j w \varsigma} \quad$ manufactured in production department $j$, after implementing project $w$, in year $\varsigma$ of its cycle, $\varsigma=t-\tau$,

$m_{d i} \quad-$ per unit consumption indicator of raw material $d$ used for producing product $i$,

$s_{d t} \quad-$ price of raw material $d$ in year $t$,

$k z_{i j w \varsigma} \quad-$ adjusted unit variable processing cost for product $i$ manufactured in production

department $j$, after implementing project $w$, in year $\varsigma$ of its cycle, $\varsigma=t-\tau$,

ris - weighted average cost of capital,

$r_{f} \quad-$ risk free rate,

$s q \quad-$ cash in hand turnover,

$c z \quad-$ inventory turnover,

$c z b \quad-$ debtor turnover,

cna - receivables turnover.

ta - tax. 
Below all designations with superscript " $o$ " refer to the state after implementation of the selected real options portfolio (portfolio of investment projects taking into account options related to these projects), with superscript " $b$ " refer to the base state (with implementation only projects nuber 0 for $J e$ departments) and with superscript " $p$ " refer to the state after implementation of the investment projects portfolio without taking into account the option (static optimal portfolio of investment projects). The following procedure are used to find the optimal portfolio of real options. For the randomly generated uncertain parameters and the selected portfolio of real options (selected $W P$ ), the following optimization task is solved.

Find

$$
\begin{aligned}
& E N P V=\sum_{t=1}^{t h} \frac{I C F_{t}^{o}-\sum_{t=0}^{t h} \eta_{t}}{\left(1+r_{f}\right)^{t}} \rightarrow \max \\
& I C F_{t}^{o}=\left(Z N_{t}^{o}+D A_{t}^{o}+Z K O_{t}^{o}\right)-\left(Z N_{t}^{b}+D A_{t}^{b}+Z K O_{t}^{b}\right) \text { for } t=1,2, \ldots, t h-1 \\
& I C F_{t}^{o}=\left(Z N_{t}^{o}+D A_{t}^{o}+Z K O_{t}^{o}+R V_{t}^{o}\right)-\left(Z N_{t}^{b}+D A_{t}^{b}+Z K O_{t}^{b}+R V_{t}^{b}\right) \text { for } t=t h \\
& \sum_{j \in J} \sum_{w \in W_{j}} \sum_{\tau=0}^{t} P r_{i j w t \tau}^{o}-\sum_{j \in J} \sum_{n \in W_{j}} \sum_{z \in I} \sum_{\tau=0}^{t} m_{i z j w \varsigma} P r_{z j w, \tau}^{o}=S R_{i t}^{o} \quad \text { for } i \in I ; t=0,1,2, \cdots, t h \\
& \sum_{i \in I_{j}} \operatorname{Pr}_{i j t w \tau}^{o} \leq \operatorname{cap}_{j \varsigma} \delta_{j w \tau} \quad \text { for } \tau=0,1,2, \cdots, \bar{\tau}, j \in J, w \in W_{j}, t=\tau, \tau+1, \tau+2, \cdots, \bar{t}_{j w} \\
& s f_{i t} \leq a c_{i t} \times m s_{i t} \\
& \text { for } i \in I ; t=0,1,2, \cdots, t h \\
& S R_{i t}^{o} \leq s f_{i t} \\
& \text { for } i \in I ; t=0,1,2, \cdots, t h
\end{aligned}
$$

Eq. (5) specifies the efficiency indicator $E N P V$ of the portfolio of real options. Eq. (6) and Eq. (7) are used to compute the cash flow of the real options portfolio in successive years of the optimization horizon. Eq. (6) concerns the years $0,1, . . t h-1$, whereas Eq. (7) concerns the last year $t h$. Cash flow is computed according to an incremental relationship, i.e. the cash flow that appears in the base state is subtracted from the cash flow which takes into account the chosen real options portfolio. In the case of searching for the optimal portfolio of real options, the production and sales of individual products of a company are optimised. $S R_{i t}^{o}$ and $P r_{i j w t \tau}^{o}$ which give the highest $E N P V$ are sought. This ensures that each year the sales of products is switched to the most profitable structure. Thanks to this, the product switch option is taken into consideration. Production and sales are determined taking into account the constraints defined by equations Eqs. (8)-(11). Eq. (8) denotes the balancing of the company's materials. It determines the distribution of production of specific products for sales and for internal production use. Eq. (9) determine development of production capacity of individual departments and production of these departments depending on the projects qualified for implementation. Eqs. (10) and (11) make sales dependent on market conditions. These equations indicate that the sales of each product can not be greater than the product of the forecasted apparent consumption and market share of the analyzed company of this product. On the basis of such defined sales and production, $Z N_{t}^{o}, D A_{t}^{o}, Z K O_{t}^{o}, R V_{t}^{o}$ used to calculate cash flows appearing in Eq. (6) and Eq. (7) are defined. A genetic algorithm is used to generate $W P$ sets. This algorithm takes into account the average value of $E N P V$ for a given $W P \overline{E N P V}_{W P}$ as fitness function and Eqs. (12)-(15) as constraints. The $\left(\overline{E N P V}_{W P}\right)$ is calculated using stochastic simulation. $W P$ generation and $\overline{E N P V}_{W P}$ calculation is repeated iteratively. If no new better solution after $L p$ iterations of the algorithm, the calculation process is terminated.

$$
\delta_{j w \tau}=\left\{\begin{array}{lr}
1 & \text { for } w \in W P \\
0 & \text { for } w \in W-W P
\end{array} \quad \text { for } \tau=0,1,2, \cdots, \bar{\tau}, j \in J, w \in W_{j}\right.
$$




$$
\begin{array}{ll}
\sum_{\tau=0}^{\tau} \delta_{j w \tau} \leq 1 & \text { for } j \in J, w \in W_{j} \\
\sum_{j \in W M_{n}} \delta_{j w \tau} \leq 1 & \text { for } n \in N \\
\sum_{j \in J} \sum_{w \in W_{j}} \sum_{\tau=0}^{t} \eta_{j w \zeta} \delta_{j w \tau} \leq \bar{\eta}_{t} . & \text { for } t=0,1,2, \cdots, t h, \varsigma=t-\tau
\end{array}
$$

The value of the binary variable $\delta_{j w \tau}$ determines the qualification of the project to the realisation or resignation from it. This variable also determines the year in which the project is implemented (year of the period $[0-\bar{\tau}])$. After establishing the values of the binary variables $\delta_{j w \tau}$, the production capacity is determined for each individual stage of the company's technological cycle. Eqs. (12)-(15) determine the feasible sets of real options portfolios. Eq. (12) indicates that the variable $\delta_{j w \tau}$ can take values 0 and 1. Eq. (13) expresses the condition that each investment project may be qualified for implementation only in one year of the period $[0-\bar{\tau}]$. The possibility of implementing individual investments in different years defines options to delay. Eq. 14 expresses the conditions that only one can be implemented among mutually exclusive projects. Eq. (15) represents the constraint that the outlays on projects qualified for implementation are lower in year $t$ than the maximum values $\bar{\eta}_{t}$ (capital rationing). In the base state (without implementation of any project) the value of sales of product $i$ is determined as the product of the forecasted apparent consumption and market share of product $i$ (Eqs. 19 and 20). Next on the basis on the amount of sales of the product $i$ the value of production of this product is defined according to the Eq. 17. Only existing aggregates working in the unaltered state is taken into account here (see Eq. 18). Sometimes, generated randomly sales may require production that is higher than the available production capacities. In this case, the sales adjustment is made so that the condition of availability of production capacity is met. Adjusted sales are determined by solving the optimization task defined by Eqs. $(16-20)$ for $t=1,2, \ldots, t h$. The objective function (16) ensures that sales will be deviating as little as possible from the sales forecast. On the basis of such defined sales and production, $Z N_{t}^{b}, D A_{t}^{b}, Z K O_{t}^{b}, R V_{t}^{b}$ used to calculate cash flows appearing in Eqs. 6 and 7 are defined.

$$
\begin{array}{lr}
\sum_{i \in I} \frac{\left|S R_{i t}^{b}-s f_{i t}\right|}{s f_{i t}} \rightarrow \min & \\
\sum_{j \in J} \sum_{w \in W_{j} \tau=0} \sum_{i=0}^{t} P r_{i j w t \tau}^{b}=S R_{i t}^{b}+\sum_{j \in J} \sum_{w \in W_{j}} \sum_{z \in I} \sum_{\tau=0}^{t} m_{i z j w \varsigma} P r_{z j w w \tau}^{b} & \text { for } i \in I \\
\sum_{i \in i_{j}} P r_{i j w \tau}^{b} \leq c a p_{j \varsigma} & \text { for } \tau=0, j \in J e, w=0 \\
S R_{i t}^{b} \leq S f_{i t} & \text { for } i \in I \\
S f_{i t}=a c_{i t} \times m s_{i t}^{b} & \text { for } i \in I
\end{array}
$$

The remaining parameters necessary to calculate the $I C F_{t}{ }^{o}$ and $I C F_{t}^{b}$ are defined according to the Eqs. (21-26) for proper sales and production.

$$
\begin{aligned}
& Z N_{t}=S P_{t}-K_{t}-\max \left(S P_{t}-K, 0\right) \times t a \quad \text { for } t=0,1, \ldots, t h \\
& S P_{t}=\sum_{i \in I} S R_{i t} \times S_{i t} \quad \text { for } t=0,1, \ldots, t h \\
& K_{t}=\sum_{j \in J} \sum_{w \in W} \sum_{j \in I_{j}} \sum_{\tau=0}^{t} k_{i j w \varsigma} P r_{i j w t \tau}+\sum_{i \in I} \sum_{d \in D} s_{d t} m_{d i} P r_{i j w t \tau}+D A_{t}+G A_{t} \quad \text { for } t=0,1, \ldots, t h \\
& Z K O_{t}=K O-K O_{t-1} \quad \text { for } t=0,1, \ldots, t h
\end{aligned}
$$




$$
\begin{array}{lr}
K O_{t}=\frac{S P_{t}}{s q}+\frac{S P_{t}}{c n a}+\frac{K_{t}-D A_{t}}{c z}-\frac{K_{t}-D A_{t}}{c z b} \quad \text { for } t=0,1, \ldots, t h \\
R V_{t}=\frac{S P_{t}}{s q}+0,7 \frac{S P_{t}}{c n a}+0,7 \frac{K_{t}-D A_{t}}{c z}-\frac{K_{t}-D A_{t}}{c z b} \quad \text { for } t=t h
\end{array}
$$

Eq. (21) show how to compute the net profit. The key problem in computing these profits is determining the revenue and total costs resulting from the analyzed scenarios. The revenue is computed using Eq. (22). Eq. (23) is used to compute the total costs. Eqs. (24-25) enable assessing the change of working capital in each year of the analyzed scenarios. The level of working capital is computed as a function of the cash in hand turnover, inventory turnover, debtor turnover and receivables turnover. Eq. (26) is used to compute the residual value for the analyzed scenarios. The residual value is computed according to the Wilcox formula, which determines that the residual value is equal to (Rebiasz et al., 2017):

$+100 \%$ of the value of means of payment, $\quad+70 \%$ of the book value of debts,

$+70 \%$ of the book value of supplies, $\quad-100 \%$ of the value of liabilities.

Changes in the company's production capacity related to the implementation of selected investment projects may cause changes in fixed costs and amortization. There arises the problem of defining the method of calculating the value of $D A_{t}, G A_{t}$. The solution of this problem is in practice to indicate which investment projects (or project portfolios in case of lack of additivity) will increase or decrease fixed costs (or amortization) and how much. Nevertheless, both the simulations and discount rate must assume risk neutrality, as when valuing options, the level of risk will change when these options are exercised. Thus, we must use the risk-free rate for discounting the incremental cash flows when the option is exercised, but these must be simulated using a risk-neutral expectation. Therefore, the $G B M$ stochastic process defined by Eq. (4) is used here to model the underlying uncertainty. The algorithm used to define optimal value of portfolio of real option is presented in Fig. 2. In the presented method, the statistical dependencies of real options are taken into consideration by using the correlated $G B M$ to determine the uncertain parameters of the economic efficiency calculation. Two types of qualitative interactions are modeled in various ways. Budget constraints (indirect interactions) are expressed in equation 15. Direct interactions are described indirectly by defined above appropriate equations of the material balances, equations used to calculate the costs and to define financial performance of the company. How do these interactions appear during calculations?. For example, the construction of a new $H R$ sheets mill characterized by lower manufacturing costs results in the possibility of transferring sheets with lower costs to subsequent phases of the technological process. This results in lower production costs in subsequent production phases. Therefore, the benefits for this reason will be taken into consideration both in existing departments and in other projects included in the portfolio increasing their economic efficiency. This affects the company's financial performance forecasts. Therefore, the impact of project complementarity will be taken into account. However, the construction of the new department of $O C$ sheet may limit (in the deficiency of production capacity of department of $H D G$ sheets) sales of $H D G$ sheets. Construction of new department of $O C$ sheet may in this case be substitutable in relation to the $H D G$ department. Therefore, the impact of project substitutability will be taken into account. In addition, these matirial balances and financial results are determined repeatedly for randomly generated parameters of the economic efficiency. Therefore, the interplay between statistical dependencies and other types of options' interactions are also taken into account in the defined method. For comparison, the static optimal portfolio of investments could be defined. The following procedure are used to find the static portfolio of investments. For the randomly generated uncertain parameters and the selected portfolio of investments (selected $W P$ ), the following optimization task is solved.

Find 


$$
\begin{aligned}
& \\
N P V & =\frac{\sum_{t=0}^{T} I C F_{t}{ }^{p}-\sum_{t=0}^{T} \eta_{0 t}}{\left(1+r_{r i s}\right)^{t}} \rightarrow \max \\
I C F_{t}{ }^{p} & =\left(Z N_{t}^{p}+D A_{t}^{p}+Z K O_{t}^{p}\right)-\left(Z N_{t}^{b}+D A_{t}^{b}+Z K O_{t}^{b}\right) \quad \text { for } t=1,2, \ldots, t h-1 \\
I C F_{t}{ }^{p} & =\left(Z N_{t}^{p}+D A_{t}^{p}+Z K O_{t}^{p}+R V_{t}^{p}\right)-\left(Z N_{t}^{b}+D A_{t}^{b}+Z K O_{t}^{b}+R V_{t}^{b}\right) \quad \text { for } t=t h
\end{aligned}
$$




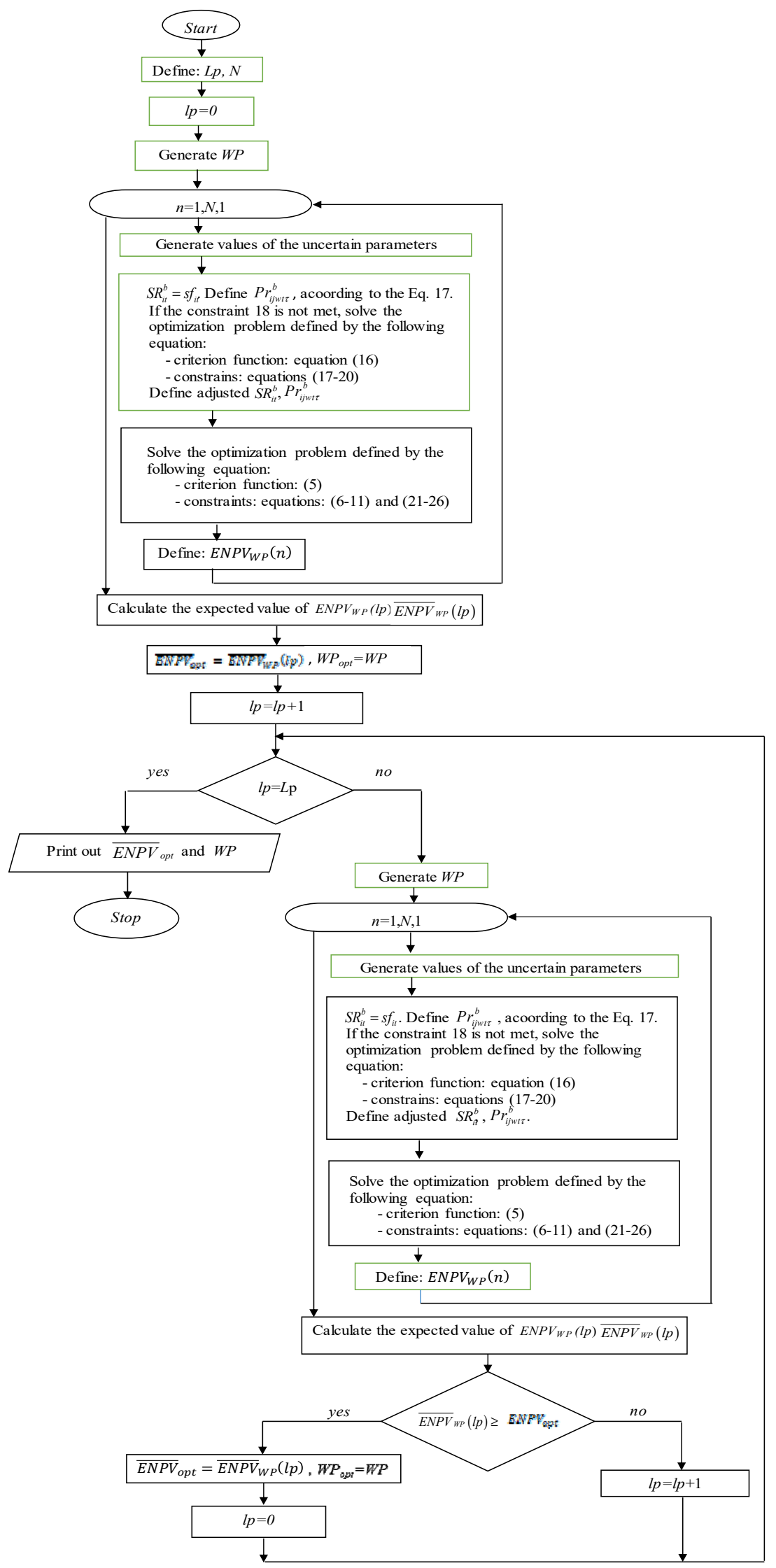

Fig. 2. The algorithm for selecting optimal value of portfolio of real options 
In case of searching for the static optimal portfolio of investments, the rules for determining sales and production are similar as in case of base state discussed above. Therefore, the switch option is not included here. However, for the sales adjustment in this case we solves optimization task defined by equations (30-34). On the basis of such defined sales and production, $Z N_{t}^{p}, D A_{t}^{p}, Z K O_{t}^{p}, R V_{t}^{p}$ used to calculate cash flows appearing in Eqs. 28 and 29 are defined.

$$
\begin{aligned}
& \sum_{i \in I} \frac{\left|S R_{i t}^{p}-s f_{i t}\right|}{s f_{i t}} \rightarrow \min \\
& \sum_{j \in J} \sum_{w \in W_{j}} \sum_{=0}^{t} \operatorname{Pr}_{i j w t \tau}^{p}=S R_{i t}^{p}+\sum_{j \in J} \sum_{w \in W_{j}} \sum_{z \in I} \sum_{\tau=0}^{t} m_{i z j w \zeta} \operatorname{Pr}_{z j w t \tau}^{p} \quad \text { for } i \in I \\
& \sum_{i \in I_{j}} \operatorname{Pr}_{i j w t \tau}^{p} \leq \operatorname{cap}_{j \varsigma} \delta_{j w \tau} \quad \text { for } \tau=0, j \in J, w \in W_{j} \\
& s f_{i t}=a c_{i t} \times m s_{i t}^{p} \quad \text { for } i \in I \\
& S R_{i t}^{p} \leq s f_{i t}
\end{aligned}
$$

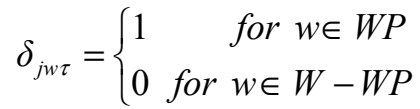

$$
\begin{aligned}
& \text { for } i \in I \\
& \text { for } \tau=0, j \in J, w \in W_{j} \\
& \sum_{j \in W M_{n}} \delta_{j w \tau} \leq 1 \quad \text { for } n \in N \\
& \eta_{t}=\sum_{j \in J} \sum_{w \in W_{j}} \eta_{j w t} \delta_{j w \tau} \leq \bar{\eta}_{t}
\end{aligned}
$$

Furthermore in case of searching of optimal portfolio of investments, it is assumed to start each investment in year $0(\tau=0)$ (see Eq. 35). Therefore, the option to delay is not included here. As above a genetic algorithm is used to generate $W P$ sets. This algorithm takes into account the average value of $N P V$ for a given $W P \overline{N P V}_{W P}$ as fitness function and Eqs. (35)-(37) as constraints. The $\left(\overline{N P V}_{W P}\right)$ is calculated using stochastic simulation. $W P$ generation and $\overline{N P V}_{W P}(l p)$ calculation is repeated iteratively. If no new better solution after $L p$ iterations of the algorithm, the calculation process is terminated. The algorithm used to select static optimal investment portfolio is presented in the Fig. 3. Statistical dependencies and qualitative interactions are defined here as in the case of defining optimal value of portfolio.

\section{Case study of selecting of optimal real options portfolio}

\subsection{Definition of the problem}

In order to illustrate the applicability and utility of the proposed method, the results of calculations for a simple model problem are presented below. Optimal options portfolio was determined for the production setup presented in Fig. 4. For the analyzed company continuous casting semi-products $(C C$ semi-products) are the basic production material. The $C C$ semi-products are converted into hot-rolled sheets ( $H R$ sheets). The $H R$ sheets are partly converted into cold-rolled sheets ( $C R$ sheets) and partly sold. The $C R$ sheets are partly sold and partly converted into hot-dip galvanized sheets (HDG sheets). The $H D G$ sheets are partly sold and partly converted into organic-coated sheets ( $O C$ sheets). The latter are all sold. Table 1 presents the considered investment projects.

\section{Table 1}

Investment projects being taken under consideration

\begin{tabular}{llc}
\hline & \multicolumn{1}{c}{ Investment project } & $\begin{array}{c}\text { Investment outlay, thousand } U S D \\
\text { (Average, standard deviation) }\end{array}$ \\
\hline 1 & Construction of the second $H R$ sheet mill & $(135000.0 ; 3375.0)$ \\
2 & Construction of the second $C R$ sheet mill & $(170000.0 ; 4250.0)$ \\
3 & Construction of second department of hot-dip galvanizing sheet, production capacity 200 thousand tonnes & $(45000,0 ; 1200)$ \\
4 & Construction of new department of $O C$ sheet, production capacity 100 thousand tonnes & $(20000.0 ; 300.0)$ \\
\hline
\end{tabular}




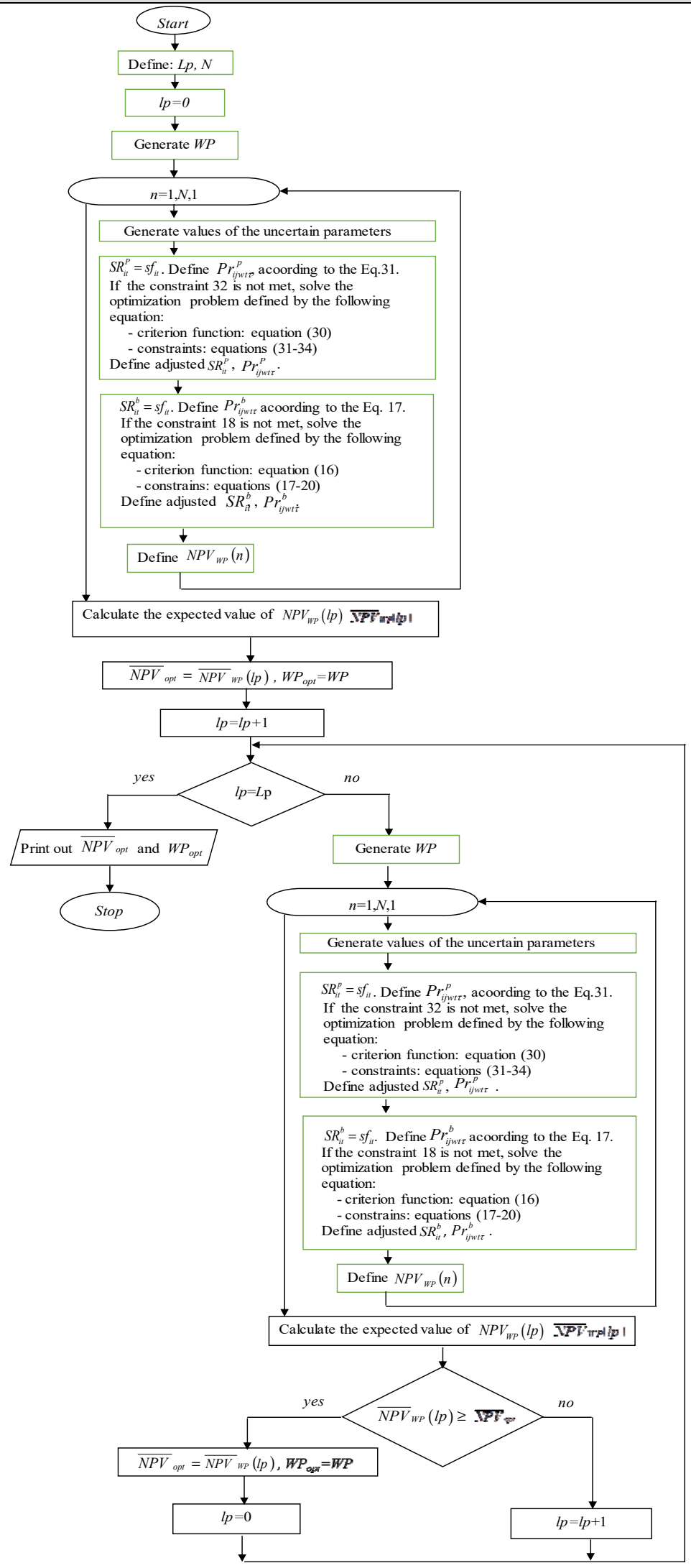

Fig. 3. The algorithm for selecting a static optimal investment portfolio 
In the computational experiment it was taken into consideration the uncertainty of the possible quantity of sales for each of products ranges being produced by the company, prices of these products, prices of $C C$ semi-products and investment outlay for analyzed projects. It was assumed, that remaining parameters were determined. Uncertainty of investment outlay for analyzed projects was modeled by probability density function (see Table 1). Remaining uncertain parameters were modeled by $G B M$ stochastic process. The $G B M$ stochastic process defined by Eq. (4) was used in case of searching optimal options portfolio. While the $G B M$ process defined by Eq. (3) was used in case of searching static optimal investment projects portfolio.

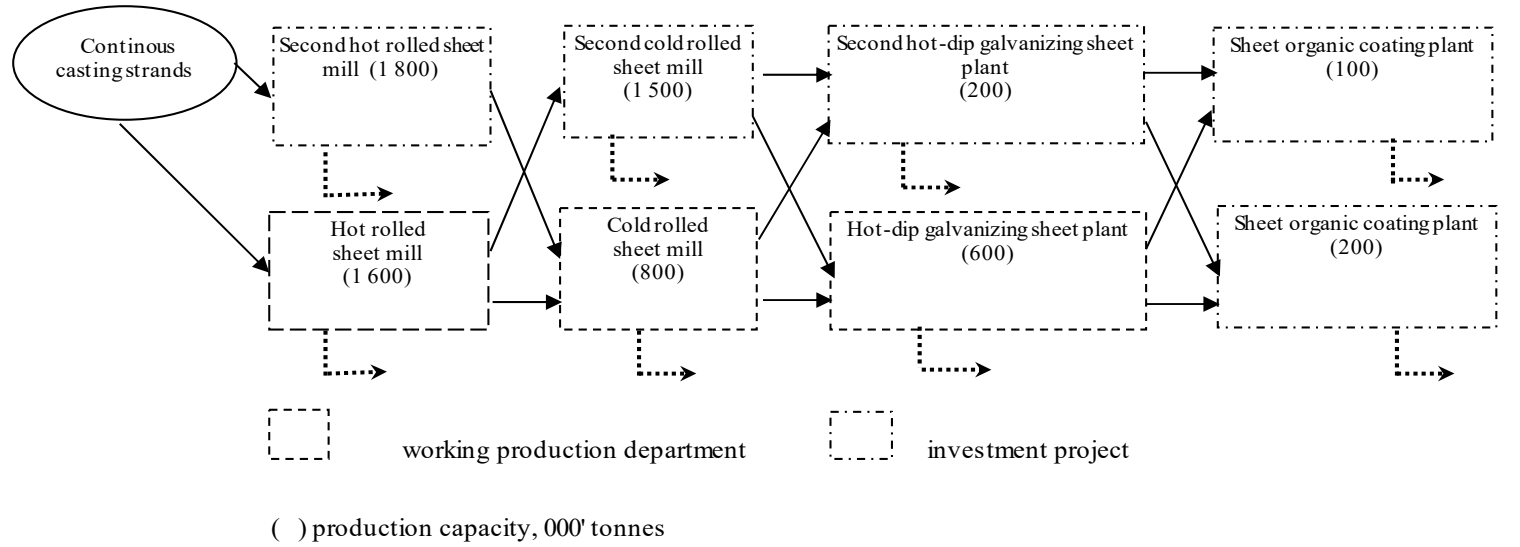

Fig. 4. Diagram of the analyzed production setup

Construction of the new department of $O C$ sheet, production capacity 100 thousand tones and new department of $O C$ sheet, production capacity 200 thousand tones were mutually exclusive projects. A maximum delay in the implementation of investment projects $(\bar{\tau})$ equal 3 was assumed for construction of the model. This assumption required using 15 binary variables. The individual binary variables determine qualification or rejection in the consecutive years $0,1,2, \ldots, \bar{\tau}$ projects listed in Table 1 . The limit of investment outlays accepted for calculations was equal US\$195 million. It was assumed that outlays not used in year $t$ are available in year $t+1$. The values placed in Tables $2-4$ were defined on the basis of analysis of the historical time series from years 1996-2017. In Table 2 is presented correlation matrix for the apparent consumption of metallurgical products manufactured by the analyzed company and in Table 3 is presented correlation matrix for the prices of the analyzed products and $C C$ semi-products.

Table 2

Correlation matrix for the apparent consumption of metallurgical products manufactured by the analyzed company

\begin{tabular}{lcccc}
\hline & $H R$ strip & $C R$ sheets & $H D G$ sheets & $O C$ sheets \\
\hline$H R$ sheets & 1.000 & 0.878 & 0.911 & 0.863 \\
$C R$ sheets & 0.878 & 1.000 & 0.915 & 0.888 \\
$H D G$ sheets & 0.911 & 0.915 & 1.000 & 0.966 \\
$O C$ sheets & 0.863 & 0.888 & 0.966 & 1.000 \\
\hline
\end{tabular}

Table 3

Correlation matrix for the prices of the analyzed products and $C C$ semi-products

\begin{tabular}{lccccc}
\hline & $C C$ semi-products & $H R$ sheet & $C R$ sheet & $H D G$ sheet & $O C$ sheet \\
\hline$C C$ semi-products & 1,000 & 0,975 & 0,964 & 0,985 & 0,984 \\
$H R$ sheet & 0,975 & 1,000 & 0,999 & 0,941 & 0,935 \\
$C R$ sheet & 0,964 & 0,999 & 1,000 & 0,926 & 0,918 \\
$H D G$ sheet & 0,985 & 0,941 & 0,926 & 1,000 & 0,960 \\
$O C$ sheet & 0,984 & 0,935 & 0,918 & 0,960 & 1,000 \\
\hline
\end{tabular}

The average growth rate per year $(\mu)$, volatility parameter $(\sigma)$ and the premiums $(\pi)$ are shown in Table 4 . Based on these values, we predict an annual price growth rate of $1.4 \%$ in common for all of the 
products, and an annual apparent consumption growth rate of $7.00 \%$ as the annual increase in demand for all products.

\section{Table 4}

The average growth rate per year $(\mu)$, volatility parameter $(\sigma)$ and the premiums $(\pi)$

\begin{tabular}{lccc}
\hline & $\begin{array}{c}\text { Average } \begin{array}{c}\text { growth rate per } \\
\text { year }(\mu)\end{array} \\
\text { For prices }\end{array}$ & Polatility parameter $(\sigma)$ & Premiums $(\pi)$ \\
\hline$C C$ semi-products & $1.44 \%$, & $15.97 \%$ & $0,82 \%$ \\
$H R$ sheet & $1.32 \%$ & $18,14 \%$ & $0.81 \%$ \\
$C R$ sheet & $1.86 \%$, & $21.09 \%$ & $0.79 \%$ \\
$H D G$ sheet & $1.60 \%$ & $19.92 \%$ & $1.01 \%$ \\
$O C$ sheet & $0.96 \%$ & $13.70 \%$ & $0.75 \%$ \\
$\quad$ For apparent consumption & & & $1.75 \%$ \\
$H R$ sheet & $7.15 \%$ & $14,33 \%$ & $1.65 \%$ \\
$C R$ sheet & $7.33 \%$ & $15,21 \%$ & $1.32 \%$ \\
$H D G$ sheet & $7.67 \%$ & $11.97 \%$ & $2.11 \%$ \\
$O C$ sheet & $8.96 \%$ & $16.64 \%$ & \\
\hline
\end{tabular}

This prediction was a result of the assumption that historical increases was partly a result of the structural changes in the sector during the economic boom, which occurred in 2006-2007. The adjusted unit variable processing costs for particular product ranges were also defined to be the values given below:

\begin{tabular}{cccccc}
\hline $\begin{array}{c}\text { Adjusted unit variable processing } \\
\text { cost, USD/tone }\end{array}$ & CC semi-products & HR sheet & CR sheets & HDG sheets & OC sheets \\
\cline { 2 - 6 } & 26.5 & 28.4 & 28.9 & 117.8 & 174.0 \\
\hline
\end{tabular}

The company's fixed costs for the base case was estimated as US\$180 million per year. The incremental fixed costs for $O C$ sheet plant capacity 100 thousand tones was estimated as US\$12.95 million per year, capacity 200 thousand tones was estimated as US\$15.00 million per year, for $H R$ sheet plant was estimated as US\$40 million per year and for $C R$ sheet plant was estimated as US\$25 million per year. The following market share values of particular product ranges were adopted in calculations:

\begin{tabular}{ccccc}
\hline \multirow{2}{*}{$\begin{array}{c}\text { Market share values of } \\
\text { particular product ranges }\end{array}$} & $H R$ sheet & $C R$ sheets & $H D G$ sheets & $O C$ sheets \\
\cline { 2 - 4 } & $50.0 \%$ & $40.0 \%$ & $46.0 \%$ & $40.0 \%$ \\
\hline
\end{tabular}

On the basis of these assumptions, the calculations were realized, the portfolio of real option and the static portfolio of investment project was defined.

\subsection{Results and discussion}

As a result of calculation the optimal real options portfolio was defined. This portfolio contains the following investment projects:

- Construction of the second $H R$ sheet mill - commencement of construction: year 0 ,

- Construction of a new department of $O C$ sheet (production capacity 200 thousand tones) commencement of construction: year 3

For comparison the static optimal investment portfolio was defined. This portfolio contained the same projects, all commencement in year 0. Fig. 5 and Fig. 6, respectively, show the probability density function of the $E N P V$ of the optimal real options portfolio and the probability density function of the $N P V$ of the static optimal investment portfolio. Table 5 summarizes the values found for the analyzed portfolios.

\section{Table 5}

The value of the efficient real options portfolio and static $N P V$ for the investment projects portfolio $N P V$ average value of the static optimal investment portfolio, thousands USD 129521.8 
As can be seen in Table 5, assuming that the prices and apparent consumption of the analyzed products follow $G B M, E N P V$ average value of the optimal real options portfolio is $47.6 \%$ bigger then $N P V$ average value of the static optimal investment portfolio. For comparison, the $E N P V$ value for several selected option portfolios is shown in Fig 7. Based on the data in Fig. 7 and Table 5, it can be concluded that switching option is the main impact on value of portfolio of real options. The impact of the option to delay is small. This can be seen clearly when we compare different portfolios containing projects launched at different times (see Fig. 7).

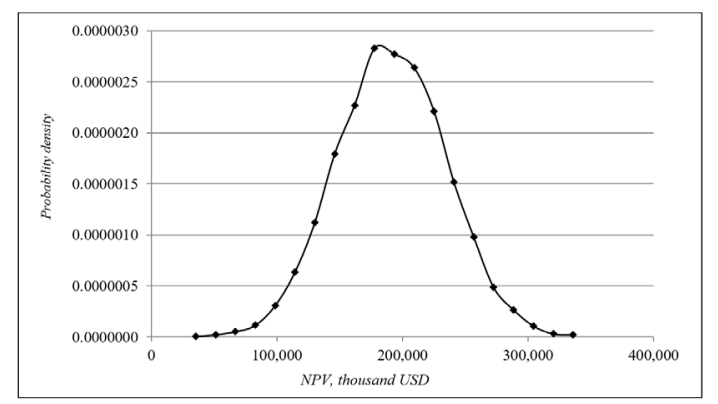

Fig. 5. The probability density function of the $E N P V$ of the optimal real options portfolio

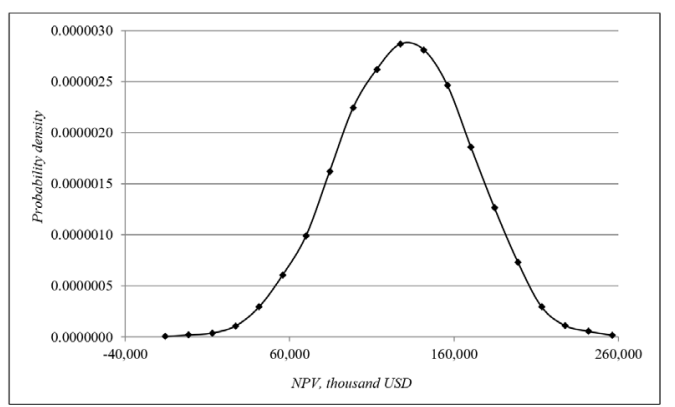

Fig. 6. The probability density function of the $N P V$ of the static optimal investment portfolio

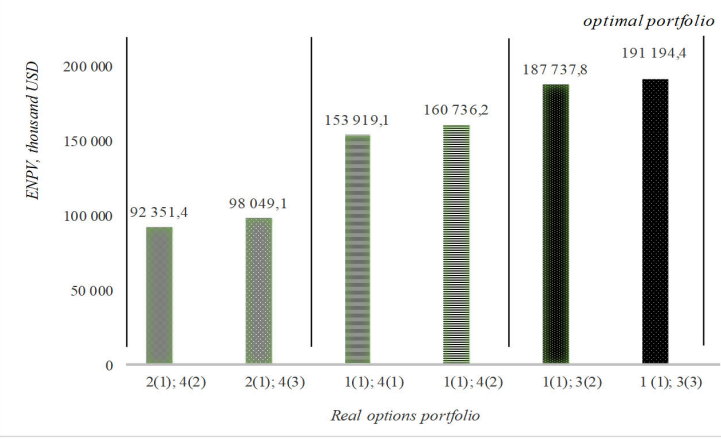

portfolio definition:

project number according to table 1 (year of project implementation $\tau$ )

Fig. 7. Comparison of $E N P V$ for selected real options portfolios

\section{Conclusion}

The concept of real option's portfolios seems to be crucial for investment valuation and defining enterprises strategies. However, the analysis of portfolios of real options in literature is limited. In this paper, we have suggested a new method of defining optimal real options portfolio. The proposed method of this paper can incorporate statistical interdependencies and any type of qualitative interactions of real options. In the proposed model, defining the interactions of options is easy and results from the concept of the model and the algorithm for selecting optimal value of portfolio of real options. Furthermore in the case of qualitative interactions the proposed method does not require the need to define new projects as in the works discussed in Section 2. A computational procedure is also proposed in order to obtain the value of real option portfolio. Completed calculations for the analyzed example indicate that, in the steel industry, real options have a significant relevance to the evaluation of a projects. For the analyzed case, it can be concluded that the switch option is the main impact on value of portfolio of real options. The impact of the option to delay is small.

\section{References}


Bastian-Pinto, C., Brandão, T. \& Hahn W.J. (2009) Flexibility as a source of value in the production of alternative fuels: The ethanol case. Energy Economics, 31, 411-422.

Betge, P. (1995). Investitionsplanung: Methoden - Modelle - Anwendungen. Wisbaden, Gabler.

Blank, F.F., Baydia, T.K.N. \& Dias M.A. (2009). Private infrastructure investment through public private partnership: An application to a toll road highway concession in Brazil. 13th Annual International Conference on Real Options, Braga, Portugal \& Santiago, Spain, pp. 1-21.

Bowe, M., \& Lee ,D.L. (2004). Project evaluation in the presence of multiple embedded real options: evidence from the Taiwan High-Speed Rail Project. Journal of Asian Economics, 15, 71-98.

Brosch, R. (2001). Portfolio-aspects in real options management, Working Paper Series: Finance \& Accounting, Faculty of Economics and Business Administration, Goethe University Frankfurt.

Brosch, R. (2008). Portfolios of Real Options, Springer-Verlag, Berlin.

Chien, C.F. (2004). A portfolio-evaluation framework for selecting R\&D projects. $R \& D$ Management, 32, 359-368.

Childs, P.D., \& Triantis, A.J. (1999). Dynamic R\&D Investment Policies. Management Science, 45, 1359-1377.

Childs, P.D., Ott, S.H. \& Triantis A.J. (1998). Capital budgeting for interrelated projects - A real options approach. Journal of Financial \& Quantitative Analysis, 33, 305-334.

Copeland, T., Koller, T., \& Murrin, J. (2015). Measuring and Managing the Value of Companies, Sixth Edition. McKinsey \& Company, John Wiley \& Sons, New York.

Denardo, E.V., Rothblum, U.G., \& Van der Heyden, L. (2004). Index policies for stochastic search in a forest with an application to R\&D project management. Mathematics of Operations Research, 29, 162-181.

Dickinson, M.W., Thomton A.C., \& Graves S. (2001). Technology portfolio management, Optimizing interdependent projects over multiple time period, IEE Transaction on Engineering Management, $48,518-527$.

Francis, J.C. (1991). Investments: Analysis and Management. McGraw-Hill, New York.

Gustafsson, J., \& Salo, A. (2005). Contingent portfolio programming for the management of risky projects. Operations Research, 53, 946-956.

Hax, H. (1985). Investionstheorie. Wurzburg-Wien 1985.

Hirsa, A., Neftci, S.N. (2014). An Introduction to the Mathematics of Financial Derivatives. Academic Press, Elsevier.

Huchzermeier, A., \& Cohen M.A. (1996). Valuing operational flexibility under exchange rate risk. Operations Research, 44, 100-113.

Hull, J.C. (2006). Options, futures and other derivatives securities (6th ed.). Englewood Cliffs, NJ: Prentice Hall.

Kasanen, E., \& Trigeorgis L. (1993). Flexibility, Synergy and Control, in Strategic Investment Planning. in: Aggarwal R. (Eds.), Capital Budgeting under Uncertainty, Prentice-Hall, Englewood Cliffs (NJ), pp. 208-231.

Kasanen, E. (1993) Creating value by spawning investment opportunities. Financial Management, 22, 251-258.

Kavadias, S., \& Loch, C.H. (2004). Project selection under uncertainty: dynamically allocating resources to maximize value. International series in operations research \& management science, Kluwer Academic Publishers, Boston (MA).

Kester, W.C. (1993). Turning Growth Options into Real Assets. in: Aggarwal R. (Eds..), Capital Budgeting under Uncertainty, Prentice-Hall, Englewood Cliffs (NJ), 187-207.

Kodukula, P., \& Papudesu, C. (2006) Project Valuation Using Real Options, A Practitioner's Guide, $J$. Ross Publishing Inc., USA.

Kogut, B., \& Kulatilaka N. (1994). Operating flexibility, global manufacturing, and the option value of a multinational network. Management Science, 40, 123-139. 
Kulatilaka, N. (1995). Operating Flexibilities in Capital Budgeting: Substitutability and Complementarity in Real Options. in: Trigeorgis L. (Eds..), Real Options in Capital Investment, Praeger, Westport (CT), 121-132.

Marathe, R., \& Ryan, S.M. (2005) On the validity of the geometric brownian motion assumption. The Engineering Economist, 50, 1-40.

Markowitz, H.M. (1952). Portfolio selection, Journal of Finance, 7, 77-91.

Meier, H., Christofides, N. \& Salkin, G. (2001), Capital budgeting under uncertainty - An integrated approach using contingent claims analysis and integer programming. Operations Research, 49, 196206.

Muharam, F.M. (2011). Assessing risk for strategy formulation in steel industry through real options analysis. Journal of Global Strategic Management, 5, 5-15.

Myers, S. (1977). Determinants of corporate borrowing. Journal of Financial Economics, 5, 147-175.

Ozorio, L.M., Bastian-Pinto, C., Baidya, T.K.N., \& Brandão, T. (2013). Investment decision in integrated steel plants under uncertainty. International Review of Financial Analysis, 27, 55-64.

Rebiasz, B. (2013). Selection of efficient portfolios-probabilistic and fuzzy approach, comparative study. Computers \& Industrial Engineering, 64, 1019-1032.

Rebiasz, B., Gaweł, B., \& Skalna, I. (2017). Valuing managerial flexibility: an application of realoption theory to steel industry investments. Operations Research and Decisions, 20, 91-111.

Rose, S. (1998). Valuation of interacting real options in a tollroad infrastructure project. Quarterly Review of Economics \& Finance, 38, 711-723.

Santhanam, R., \& Kyparisis, G.J. (1996). A decision model for interdependent information system project selection. European Journal of Operational Research, 89, 380-399.

Smith, J.L., \& Thompson, R. (2008). Managing a portfolio of real options: Sequential exploration of dependent prospects. The Energy Journal, International Association for Energy Economics, 29, 4362 .

Triantis, A.J. (2005). Realizing the potential of real options: Does theory meet practice?. Journal of Applied Corporate Finance, 17, 8-16.

Triantis, A.J., \& Hodder, J.E. (1990). Valuing flexibility as a complex option. Journal of Finance, 45, 549-565.

Trigeorgis, L., \& Kasanen, E. (1991). An integrated options-based strategic planning and control model. Managerial Finance, 17, 16-28.

Trigeorgis, L. (1993). The nature of option interactions and the valuation of investments with multiple real options. Journal of Financial \& Quantitative Analysis, 28, 1-20.

Trigeorgis, L. (1996). Real Options - Managerial Flexibility and Strategy in Resource Allocation. $4^{\text {th }}$ ed., MIT Press, Cambrigde (MA).

Vassolo, R.S., Anand, J., \& Folta T.B. (2004). Nonadditivity in portfolios of exploration activities: A real options-based analysis of equity alliances in biotechnology. Strategic Management Journal, 25, $1045-1061$.

Wang, T., \& de Neufville R. (2004) Building real options into physical systems with stochastic mixedinteger programming. Working Paper, 8th Annual International Conference on Real Options, 2004, pp. 1-35.

Wasilewska, M. (2013) Comparison between portfolios of real options and portfolios of financial options. Research Papers of Wroclaw University of Economics, 290, 128-135.

Wattanarat, V., Phimphavong, P., \& Matsumaru, M. (2010) Demand and price forecasting models for strategic and planning decisions in a supply chain. Proceedings of the School of Information and Telecommunication Engineering, Tokai University, 3, 37-42.

Yang, I.T. (2005). Simulation-based estimation for correlated cost elements. International Journal of Project Management, 23, 275-282.

Zuluaga, A., Sefair J., \& Medaglia, A. (2007). Model for the Selection and Scheduling of Interdependent Projects. Proceedings of the 2007 Systems and Information Engineering Design Symposium, Charlottesville, VA, IEEE, 1-7. 


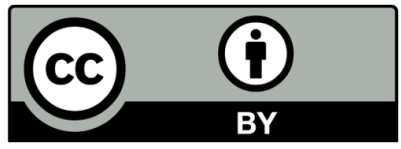

(C) 2020 by the authors; licensee Growing Science, Canada. This is an open access article distributed under the terms and conditions of the Creative Commons Attribution (CC-BY) license (http://creativecommons.org/licenses/by/4.0/). 